Research article

\title{
Insights in to the pathogenesis of axial spondyloarthropathy based on gene expression profiles
}

\author{
Srilakshmi M Sharma ${ }^{1}$, Dongseok Choi $^{2}$, Stephen R Planck ${ }^{1,3,4}$, Christina A Harrington ${ }^{5}$, \\ Carrie R Austin ${ }^{1}$, Jinnell A Lewis ${ }^{1}$, Tessa N Diebel ${ }^{1}$, Tammy M Martin ${ }^{1,6}$, Justine R Smith ${ }^{1,3}$ and \\ James T Rosenbaum ${ }^{1,3,4}$
}

\author{
${ }^{1}$ Casey Eye Institute, Oregon Health \& Science University, 3181 SW Sam Jackson Park Road, Portland, Oregon, 97239, USA \\ ${ }^{2}$ Department of Public Health \& Preventive Medicine, Oregon Health \& Science University, 3181 SW Sam Jackson Park Road, Portland, Oregon, \\ 97239, USA \\ ${ }^{3}$ Department of Cell \& Developmental Biology, Oregon Health \& Science University, 3181 SW Sam Jackson Park Road, Portland, Oregon, 97239 , \\ USA \\ 4Department of Medicine, Oregon Health \& Science University, 3181 SW Sam Jackson Park Road, Portland, Oregon, 97239, USA \\ ${ }^{5}$ Gene Microarray Shared Resource, Oregon Health \& Science University, 3181 SW Sam Jackson Park Road, Portland, Oregon, 97239 , USA \\ ${ }^{6}$ Department of Molecular Microbiology \& Immunology, Oregon Health \& Science University, 3181 SW Sam Jackson Park Road, Portland, Oregon, \\ 97239, USA
}

Corresponding author: James T Rosenbaum, rosenbaj@ohsu.edu

Received: 26 May 2009 Revisions requested: 20 Jul 2009 Revisions received: 29 Sep 2009 Accepted: 9 Nov 2009 Published: 9 Nov 2009

Arthritis Research \& Therapy 2009, 11:R168 (doi:10.1186/ar2855)

This article is online at: http://arthritis-research.com/content/11/6/R168

(c) 2009 Sharma et al.; licensee BioMed Central Ltd.

This is an open access article distributed under the terms of the Creative Commons Attribution License (http://creativecommons.org/licenses/by/2.0), which permits unrestricted use, distribution, and reproduction in any medium, provided the original work is properly cited.

\begin{abstract}
Introduction Axial spondyloarthropathy $(\mathrm{SpA})$ is a group of inflammatory diseases, with ankylosing spondylitis as the prototype. SpA affects the axial skeleton, entheses, joints and, at times, the eyes. This study tested the hypothesis that SpA is characterized by a distinct pattern of gene expression in peripheral blood of affected individuals compared with healthy controls.

Methods High-density, human GeneChip ${ }^{\circledR}$ probe arrays were used to profile mRNA of peripheral blood cells from 18 subjects with SpA and 25 normal individuals. Samples were processed as two separate sets at different times ( $11 \mathrm{SpA}+12$ control subjects in primary set (Set 1); $7 \mathrm{SpA}+13$ control subjects in the validation set (Set 2)). Blood samples were taken at a time when patients were not receiving systemic immunomodulatory therapy. Differential expression was defined as a 1.5 -fold change with a q value $<5 \%$. Gene ontology and pathway information were also studied.

Results Signals from 134 probe sets (representing 95 known and 12 unknown gene transcripts) were consistently different

from controls in both Sets 1 and 2 . Included among these were transcripts for a group of 20 genes, such as interleukin-1 (IL-1) receptors 1 and 2, Nod-like receptor family, pyrin domain containing 2 (NLRP2), secretory leukocyte peptidase inhibitor (SLPI), secreted protein acidic and rich in cysteine (SPARC), and triggering receptor expressed on myeloid cells 1 (TREM-1) that are clearly related to the immune or inflammatory response and a group of 4 transcripts that have a strong role in bone remodeling.

Conclusions Our observations are the first to implicate SPARC, SLPI, and NLRP2, a component of the innate immune system, in the pathogenesis of SpA. Our results also indicate a possible role for IL-1 and its receptors in SpA. In accord with the bone pathology component of $\mathrm{SpA}$, we also found that expression levels of transcripts reflecting bone remodeling factors are also distinguishable in peripheral blood from patients with SpA versus controls. These results confirm some previously identified biomarkers implicated in the pathogenesis of SpA and also point to novel mediators in this disease.
\end{abstract}

BMP: bone morphogenetic protein; CEL: cell fluorescence intensity; DKK-1: Dickkopf-1; GCOS: GeneChip Operating System; GC-RMA: GC Robust Multiarray Analysis; IL-1: interleukin-1; IL-1R: interleukin-1 receptor; NLRP2 (NALP2): Nod-Like Receptor family, pyrin domain containing 2; OHSU: Oregon Health \& Science University; PM: perfect match; SAM: Significance Analysis of Microarrays; SLPI: secretory leukocyte peptidase inhibitor; SpA: axial spondyloarthropathy; SPARC: secreted protein acidic and rich in cysteine (also known as osteonectin); TNF: tumor necrosis factor; TREM-1: triggering receptor expressed on myeloid cells 1. 


\section{Introduction}

Axial spondyloarthropathy $(\mathrm{SpA})$ is a family of polygenic inflammatory diseases for which the pathophysiology is complex, with much remaining unknown. Ankylosing spondylitis is the most common form of SpA. Study of gene expression using microarrays offers a novel approach to determining pathogenesis of diseases. Analysis of peripheral blood in patients with systemic lupus erythematosus using this technique has led to the discovery that many lupus patients have an upregulation of genes induced by type I interferons [1].

The present study utilizes a methodology that incorporates an experimental design consisting of primary and validation datasets of subjects, a comprehensive microarray platform, and robust statistical techniques to investigate the presence of a $\mathrm{SpA}$ gene expression signature and the presence of novel biomarkers of disease.

\section{Materials and methods Subjects}

This study is in compliance with the Helsinki Declaration and was approved by the Oregon Health \& Science University (OHSU) Institutional Review Board. Patients with SpA attending the Uveitis or Rheumatology Clinics at OHSU were recruited to this study and informed consent was obtained before samples were collected. SpA was diagnosed based on the calculation of a likelihood score, as described by Rudwaleit and colleagues [2]. A diagnosis of SpA is made if the likelihood ratio product for all positive factors exceeds 200 $[3,4]$. Because patients were attending an eye disease clinic, joint disease activity was not formally assessed. However, the likelihood ratio indicates a $90 \%$ probability that the subjects have SpA. Ulcerative colitis in one patient was permitted in the $\mathrm{SpA}$ group because it is known that SpA may co-exist with inflammatory bowel disease [4]. One patient had psoriasis. All other autoimmune diseases were excluded. Chronic systemic conditions were allowed, as were medications for co-existent morbidities. Systemic immunomodulatory therapy was not permitted. Only one patient is known to have received a TNF inhibitor (etanercept), and this had been discontinued two months prior to the blood draw for this study.
Gene expression in these subjects was compared with that in 25 healthy control subjects without a history of autoimmune disease. Tables 1, 2 and 3 contain demographic and clinical information for the SpA and healthy control subjects. Male subjects in the SpA group outnumbered females as is characteristic of this disease. Neither SpA nor control subjects were on oral corticosteroids or other immunomodulatory therapy. Samples were processed and the results analyzed as two separate datasets, a primary set and validation set, at two different times.

\section{Gene expression microarray}

Unfractionated whole blood collection and RNA isolation were performed using the PAXgene Blood RNA Isolation System (PreAnalytiX, a Qiagen BD Company, Valencia, CA, USA) according to the manufacturer's recommendation. Microarray assays were performed in the Affymetrix Microarray Core, a unit of the OHSU Gene Microarray Shared Resource. Total RNA was amplified and labeled using a one-cycle target-labeling method modified to reduce globin mRNA targets (GeneChip Globin Reduction Protocol rev.1; Affymetrix, Inc., Santa Clara, CA, USA) and hybridized according to the manufacturer. The high density, human GeneChip ${ }^{\circledR}$ probe arrays (HGU133 Plus 2.0, Affymetrix, Inc, Santa Clara, CA, USA) were used. Each array contains 54,000 probe sets designed to analyze the expression of 47,000 human transcripts and variants.

Hybridized arrays were processed using the Fluidics Station 450 (Affymetrix, Inc, Santa Clara, CA, USA) and distribution of fluorescence was measured using the Gene Chip Scanner 3000 (Affymetrix, Inc, Santa Clara, CA, USA). Cell fluorescence intensity (CEL) files were generated using the Gene Chip Operating System (GCOS) software version 1.2 (Affymetrix, Inc, Santa Clara, CA, USA).

\section{Statistical analysis}

The 'affy' and 'gcrma' packages of Bioconductor [5] were used to preprocess and normalize the data following import of CEL files into the $R$ statistical package (Affymetrix, Inc, Santa Clara, CA, USA). The GC Robust Multiarray Analysis (GCRMA) was used to adjust perfect match (PM) probe data for background noise [6]. Normalization was performed on adjusted PM data with an algorithm based on rank invariant

Table 1

\section{Dataset characteristics}

\begin{tabular}{|c|c|c|c|c|c|c|}
\hline & \multicolumn{2}{|c|}{ Dataset 1} & \multicolumn{2}{|c|}{ Dataset 2} & \multicolumn{2}{|c|}{ Combined sets } \\
\hline & SpA & Control & SpA & Control & SpA & Control \\
\hline Age (mean \pm SD) & $51.8 \pm 12.8$ & $48.8 \pm 21.4$ & $46.7 \pm 14.5$ & $35.4 \pm 9.7$ & $49.7 \pm 12.9$ & $41.8 \pm 17.4$ \\
\hline Years since SpA diagnosis (mean \pm SD) & $16.2 \pm 14.9$ & & $8.2 \pm 11.2$ & & $13.7 \pm 14.0$ & \\
\hline Males/females & $9 / 2$ & $4 / 8$ & $4 / 3$ & $1 / 12$ & $13 / 5$ & $5 / 20$ \\
\hline
\end{tabular}


Table 2

\begin{tabular}{|c|c|c|c|c|c|}
\hline Subject & Dataset & Gender & Race & SpA Likelihood ratio & Medications \\
\hline 1 & 1 & M & Asian & 4073 & None (Etanercept withdrawn for 2 months) \\
\hline $2^{*}$ & 1 & M & Caucasian & 204 & $\begin{array}{c}\text { Simvastatin, cyclobenzaprine, aspirin, indomethacin, atenolol, lansoprazole, } \\
\text { hydrocodone }\end{array}$ \\
\hline 3 & 1 & M & Caucasian & 204 & - \\
\hline 4 & 1 & M & Caucasian & 4073 & - \\
\hline 5 & 1 & M & Caucasian & 934 & - \\
\hline 6 & 1 & M & Asian & 204 & - \\
\hline 7 & 1 & M & Caucasian & 4073 & $\begin{array}{c}\text { Metformin, glipizide, atorvastatin, lisinopril, nifedipine, Lantus insulin, Novo } \\
\text { Log, sulfasalazine, indomethacin }\end{array}$ \\
\hline 8 & 1 & M & Caucasian & 558 & Ibuprofen \\
\hline 9 & 1 & $\mathrm{~F}$ & Caucasian & 11383 & Piroxicam, indomethacin \\
\hline 10 & 1 & $\mathrm{~F}$ & Caucasian & 7115 & Rofecoxib \\
\hline 11 & 1 & M & Caucasian & 255 & Acetaminophen, ramipril, omeprazole, aspirin, atorvastatin \\
\hline 12 & 2 & M & Caucasian & 4073 & $\begin{array}{l}\text { Insulin, nifedipine, glipizide, lisinopril, metformin, Vicodin, Flexeril, } \\
\text { indomethacin, sulfasalazine }\end{array}$ \\
\hline 13 & 2 & $\mathrm{~F}$ & Caucasian & 1039 & Celecoxib, trazodone, venlafaxine, ranitidine \\
\hline 14 & 2 & $\mathrm{~F}$ & Caucasian & 204 & Tobramycin \\
\hline 15 & 2 & $\mathrm{~F}$ & Asian & 4073 & Alendronate \\
\hline 16 & 2 & M & Asian & 204 & - \\
\hline 17 & 2 & M & Caucasian & 20774 & Phenylbutazone \\
\hline 18 & 2 & $M$ & Caucasian & 2308 & Alendronate sodium \\
\hline
\end{tabular}

${ }^{*}$ coexistent ulcerative colitis. $\mathrm{F}=$ female; $\mathrm{M}=$ male; $\mathrm{SpA}=$ axial spondyloarthropathy.

probes [7]. After normalization, differential gene expression between groups was assessed by Significance Analysis of Microarrays (SAM) [8]. Differential expression was defined as a 1.5 -fold change with a $q$ value less than $5 \%$. The $q$ value is a Bayesian equivalent to the false discovery rate adjusted $P$ value [9]. Statistical analysis was performed at an array probe set level; transcript counts were corrected for the presence of multiple probe sets. These data have been used to illustrate an analytical approach described in a statistical methods paper [10] and the controls were also used in a parallel study on gene expression in patients with sarcoidosis [11]. The raw and normalized data have been deposited in the Gene Expression Omnibus repository [GEO: GSE18781] [12].

As males predominated among the $\mathrm{SpA}$ subjects and females were more common in the control group, we took additional caution to exclude conclusions attributable to gender. To identify possible gender effects on gene expression levels that might confound interpretation of the intergroup comparisons, an analysis was conducted to determine which of the following four linear models best fit the data for each probe set: (1) a model in which gene expression is impacted by disease state alone; (2) a model in which gender is the sole influence on gene expression; (3) a model in which, after controlling for gender effects, the principal effects are due to disease state; and (4) a model in which the interaction between disease state and gender also influences the results. For this analysis, data from both sets were first renormalized using the quantile normalization method [13]. The well-established Akaike's information criterion [14] was then used to choose the best among four models for each probe set shown in Tables 4 and 5 based on likelihood calculations.

\section{Pathway analysis of gene expression results}

Each gene was studied using a network analysis module within MetaCore ${ }^{\mathrm{TM}}$ bioinformatics software (GeneGo Inc, St. Joseph, MI, USA) [15] to identify known functional associations between genes identified in our study and other genes or pathways. These curated networks may include transcription factors, receptors, and enzyme cascades.

\section{Results}

Gene expression microarray analysis was performed on whole blood collected from two independent sets of SpA and control subjects. Our analysis of Set 1 identified 556 probe sets that were upregulated and 962 probe sets that were downregu- 
Table 3

\begin{tabular}{|c|c|c|c|c|}
\hline Subject & Data-set & Gender & Race & Medications \\
\hline 19 & 1 & $\mathrm{~F}$ & Caucasian & Alphagan OP, Xalatan OP \\
\hline 20 & 1 & $\mathrm{~F}$ & Caucasian & - \\
\hline 21 & 1 & $\mathrm{~F}$ & Caucasian & Atorvastatin, losartan, atenolol, aspirin, hydrochlorothiazide \\
\hline 22 & 1 & M & Caucasian & Atorvastatin, glargine, lisinopril, fluoxetine, amlodipine, Systane OP \\
\hline 23 & 1 & $\mathrm{~F}$ & Caucasian & Levothyroxine, sertraline \\
\hline 24 & 1 & M & Caucasian & Diazepam, simvastatin, aspirin \\
\hline 25 & 1 & M & Caucasian & Ibuprofen \\
\hline 26 & 1 & $\mathrm{~F}$ & Caucasian & - \\
\hline 27 & 1 & $\mathrm{~F}$ & Caucasian & Sertraline, desogestrel/ethinyl estradiol \\
\hline 28 & 1 & M & Caucasian & Ibuprofen, diazepam, acetaminophen/aspirin, esomeprazole, sumatriptan \\
\hline 29 & 1 & $\mathrm{~F}$ & Caucasian & - \\
\hline 30 & 1 & $\mathrm{~F}$ & Asian & Trazodone, sertraline, levonorgestrel/ethinyl, estradiol, atorvastatin, ibuprofen, acetaminophen \\
\hline 31 & 2 & $\mathrm{~F}$ & Caucasian & Acetaminophen, ibuprofen \\
\hline 32 & 2 & $\mathrm{~F}$ & Caucasian & - \\
\hline 33 & 2 & $\mathrm{~F}$ & Mixed* $^{*}$ & - \\
\hline 34 & 2 & $\mathrm{~F}$ & Caucasian & Ibuprofen \\
\hline 35 & 2 & $\mathrm{~F}$ & Caucasian & Etonogestrel/ethinyl estradiol VA \\
\hline 36 & 2 & $\mathrm{~F}$ & Caucasian & - \\
\hline 37 & 2 & $\mathrm{~F}$ & Caucasian & Etonogestrel/ethinyl estradiol VA, cetirizine \\
\hline 38 & 2 & $\mathrm{~F}$ & Caucasian & Desogestrel/ethinyl estradiol \\
\hline 39 & 2 & $\mathrm{~F}$ & Caucasian & - \\
\hline 40 & 2 & $\mathrm{~F}$ & Caucasian & Estradiol $0.01 \%$ cream, levonorgestrel \\
\hline 41 & 2 & M & Caucasian & - \\
\hline 42 & 2 & $\mathrm{~F}$ & Caucasian & Duloxetine, valacyclovir, cyclobenzaprine \\
\hline 43 & 2 & $\mathrm{~F}$ & Caucasian & - \\
\hline
\end{tabular}

${ }^{*}$ mixed race is seven out of eight Caucasian and one out of eight African-American.

lated in subjects with $\mathrm{SpA}$ compared with healthy control subjects. Because some transcript levels were evaluated by multiple probe sets on the microarray chip, the chosen probe sets corresponded to 369 upregulated gene transcripts and 721 downregulated gene transcripts. In Set 2, 704 probe sets (550 gene transcripts) were upregulated; 14 probe sets (7 gene transcripts) were downregulated in patients with SpA relative to the control subjects. Heat maps illustrate differences between the groups [see Additional data file 1]. There were 124 probe sets (92 known and 10 unidentified gene transcripts) that were classified in both sets as upregulated in SpA subjects; 10 probe sets ( 3 known and 2 unidentified gene transcripts) were downregulated in both sets [see Additional data file 2].
We conducted a literature search using National Center for Biotechnology Information databases, including PubMed [16], on all significantly over- or underexpressed gene transcripts to determine their biological functions. Within the group of transcripts identified in both sets, there were 20 gene transcripts involved in immunity or inflammation that might constitute part of the immune signature in SpA. Table 4 presents these transcripts with functional annotations. In particular, we found upregulation of $\mathrm{IL}-1$ receptors and the downregulation of a potential regulator of the IL-1 pathway, NLRP2. Other upregulated transcripts of interest included 'secreted protein acidic and rich in cysteine' (SPARC) and secretory leukocyte peptidase inhibitor (SLPI). Four gene transcripts that have a role in bone remodeling, including kremen 1, were differentially 


\begin{tabular}{|c|c|c|c|c|c|c|}
\hline \multirow[b]{2}{*}{ Gene symbol } & \multirow[b]{2}{*}{ Gene name } & \multicolumn{2}{|l|}{ Set 1} & \multicolumn{2}{|l|}{ Set 2} & \multirow[b]{2}{*}{ Function } \\
\hline & & Fold change & Q (\%) & Fold change & Q (\%) & \\
\hline$A L O X 12^{*}$ & Arachidonate 12-lipoxygenase & 1.7 & 2.4 & 1.9 & 2.1 & $\begin{array}{l}\text { Arachidonic acid metabolism; } \\
\text { inflammatory response }\end{array}$ \\
\hline$B C L 6^{*}$ & B-cell CLL/lymphoma 6 & 1.8 & 2.4 & 1.7 & 1.5 & $\begin{array}{l}\text { Pleiotropic action in immune response. } \\
\text { Inhibits B cell apoptosis }\end{array}$ \\
\hline$C L U$ & Clusterin & 1.5 & 2.4 & 1.9 & 2.1 & Complement regulatory action \\
\hline CR1 & $\begin{array}{l}\text { Complement component }(3 \mathrm{~b} / \\
4 \mathrm{~b}) \text { receptor } 1\end{array}$ & 1.5 & 2.4 & 1.9 & 1.0 & $\begin{array}{l}\text { Complement receptor, regulates B cell } \\
\text { apoptosis, immune complex clearance }\end{array}$ \\
\hline$D E F A 4^{*}$ & Defensin, alpha 4 , corticostatin & 2.1 & 2.4 & 4.2 & 1.2 & Non-specific immune response \\
\hline FAM3B & $\begin{array}{l}\text { Family with sequence similarity } \\
\qquad 3, \text { member } B\end{array}$ & 4.9 & 2.4 & 3.6 & 1.0 & IL1-like activity \\
\hline GRB10* & $\begin{array}{l}\text { Growth factor receptor-bound } \\
\text { protein } 10\end{array}$ & 1.8 & 2.4 & 1.5 & 1.0 & $\begin{array}{l}\text { Regulator of nuclear factor kappa B } \\
\text { (NFKB) }\end{array}$ \\
\hline$I L 1 R 1^{*}$ & Interleukin 1 receptor type I & 1.6 & 2.4 & 2.0 & 0.4 & Binds to IL1 \\
\hline IL1R2* & Interleukin 1 receptor, type II & 1.6 & 2.4 & 1.8 & 1.5 & Decoy target for IL1 \\
\hline MAPK14* & $\begin{array}{l}\text { Mitogen-activated protein kinase } \\
14\end{array}$ & 1.5 & 2.4 & 1.6 & 1.8 & Part of the MAPK cascade \\
\hline NCR3 & $\begin{array}{l}\text { Natural cytotoxicity triggering } \\
\text { receptor } 3\end{array}$ & -2.5 & 4.9 & -1.7 & 1.5 & $\begin{array}{l}\text { Required for NK cell-mediated induction of } \\
\text { dendritic cell maturation }\end{array}$ \\
\hline NLRP2/NALP2* & $\begin{array}{l}\text { NLR family, pyrin domain } \\
\text { containing } 2\end{array}$ & -2.5 & 4.3 & -1.7 & 1.5 & $\begin{array}{l}\text { Part of the inflammasome; inhibits NFkB. } \\
\text { Causes caspase-1 activation }\end{array}$ \\
\hline PTGS1/COX1 & Cyclooxygenase 1 & 1.9 & 2.4 & 1.8 & 2.1 & Prostaglandin synthesis. \\
\hline SELP & Selectin P (CD62) & 1.7 & 2.4 & 1.6 & 4.1 & $\begin{array}{l}\text { Extra-lymphoid T cell recruitment. } \\
\text { Mediates Endothelial cell and leucocyte } \\
\text { interaction }\end{array}$ \\
\hline$S L P I^{*}$ & $\begin{array}{l}\text { Secretory leukocyte peptidase } \\
\text { inhibitor }\end{array}$ & 2.0 & 2.4 & 2.4 & 1.0 & $\begin{array}{l}\text { Antimicrobial activity; innate host defense } \\
\text { mechanism }\end{array}$ \\
\hline SOD2 & Superoxide dismutase 2 & 1.7 & 2.4 & 2.8 & 1.5 & $\begin{array}{l}\text { Free radical scavenging enzyme involved } \\
\text { in defense against oxidative stress }\end{array}$ \\
\hline SPARC & $\begin{array}{l}\text { Secreted protein, acidic, } \\
\text { cysteine-rich (osteonectin) }\end{array}$ & 3.1 & 2.4 & 2.3 & 0.8 & Involved in $\mathrm{T}$ cell activity and ossification \\
\hline$T H B D^{*}$ & Thrombomodulin & 1.5 & 2.4 & 1.7 & 3.1 & Innate immune response activity \\
\hline THBS1 & Thrombospondin 1 & 2.0 & 2.4 & 2.0 & 2.5 & Glycoprotein \\
\hline TREM1 & $\begin{array}{l}\text { Triggering receptor expressed } \\
\text { on myeloid cells-like } 1\end{array}$ & 1.9 & 2.4 & 2.1 & 2.5 & Amplifies response of NLRP2 \\
\hline
\end{tabular}

Significantly differentially expressed genes with a recognized immune or inflammation-related function present in Set 1 and Set 2 . Functional annotations were obtained from Online Mendelian Inheritance in Man database [32]. *Secondary analysis indicates that expression level changes are more apparent in males.

expressed (Table 5). These might form part of a bone remodeling signature for SpA.

Because of a disproportionate number of females in the control group, we conducted a post hoc analysis of variance on the effect of gender. Four models based on different effects of gender and disease state on gene expression were considered. Akaike's information criterion was used to select the model that best fits the data for each probe set. For 14 of the
24 genes included in this secondary analysis, Akaike's information criterion selected the model that assigned the principle expression differences to the disease state after correcting for a gender effect (model 3 in the methods section). The model selected for the remaining 10 genes (marked with an asterisk in Tables 4 and 5) also included an interaction effect of disease state and gender (model 4). For these genes, male subjects with SpA had higher fold-changes than both control subjects and female subjects with $\mathrm{SpA}$, and we cannot 


\begin{tabular}{cccccccc}
\hline Bone remodeling signature & & & & & & & \\
\hline
\end{tabular}

*Secondary analysis indicates that expression level changes are more apparent in males.

exclude a possible effect of gender on the level of transcript expression. However, as an example, even if the downregulation of NLRP2 is a result of the male predominance in the disease group, it would nonetheless represent a novel insight into the male predisposition to SpA.

\section{Discussion}

There are few published studies of gene expression in SpA. Our study reveals a number of genes that are differentially expressed in peripheral blood of patients with SpA and that can be related to the current understanding of its pathogenesis. Our study differs from prior studies in a variety of methodological ways including the number of transcripts studied (more than 47,000 per subject), the exclusion of patients on disease-modifying medications, the use of whole blood, which avoids the potential artifact induced by isolating leukocytes or leukocyte subsets, and pathway analysis in silico. Use of a primary dataset and an independent validation dataset provides additional robustness. Utilizing a false discovery rate calculation limits the possibility of false positives due to chance alone.

Almost all of the transcripts identified as having increased or decreased expression [see Additional data file 2] deserve comment with regard to the pathogenesis of $\mathrm{SpA}$, but space precludes such a thorough discussion. We have selected a small number of transcripts for additional comment. The detection of a set of gene transcripts that may have a role in the immune response and are differentially expressed in both datasets suggests the presence of an 'immune signature' in SpA. Prior work has strongly implicated the IL-1 family in the pathogenesis of SpA. Increased IL-1 $\beta$ mRNA has been found in peripheral blood profiling in individuals with spondyloarthropathy [17]. Genetic studies have found that polymorphisms in the IL-1 gene family are associated with ankylosing spondylitis [18] and psoriatic arthritis [19]. The finding that both IL-1 receptor (IL-1R) 1 and IL-1R2 are increased at a transcript level suggests a possible correlation with a genetic association between ERAP1 (ARTS1) polymorphisms and ankylosing spondylitis [20]; ERAP1 is a proteinase believed to lessen immune responses by cleaving receptors for cytokines including IL-1. Triggering receptor expressed on myeloid cells (TREM)-1 has also previously been implicated in the pathogenesis of ankylosing spondylitis [21]. The detection of transcripts that have independently been implicated in SpA adds to the credibility of gene expression microarray analysis as a technique to identify causal factors in this disease.

SLPI has not previously been implicated in the pathogenesis of SpA. SLPI, however, downregulates the synthesis of TNF $\alpha$ [22] and, as such, may well play an important role in the pathogenesis of this disease that often responds markedly to TNF inhibition. SPARC, which is also known as osteonectin, has been implicated in the pathogenesis of scleroderma [23], but not SpA. SPARC could logically be listed as a contributor to bone remodeling (see below), but it also negatively regulates dendritic cell migration and T cell activation [24].

The reduced expression of Nod-Like receptor family, pyrin domain containing 2 (NLRP2 or NALP2) is a novel observation and is especially intriguing. NLRP2 is a component of some inflammasomes [25] and is a member of the NLR family of proteins many of which function as danger-associated molecular pattern receptors of the innate immune system. Polymorphisms in other NLR and related genes have been implicated in diseases that share clinical features with $\mathrm{SpA}$, including Behçet's disease, Crohn's disease, and psoriatic arthritis. Polymorphisms or mutations in genes encoding components or regulators of inflammasomes are associated with several autoinflammatory diseases. NLRP2 functions as an intracellular pattern recognition receptor whose downstream function includes activation of caspase 1 and inhibition of nuclear factor kappa $B$, both of which lead to regulation of IL-1 $\beta$ (Figure 1) $[26,27]$. The downregulation of NLRP2 may therefore lead to upregulation of $\mathrm{IL}-1 \beta$, which in turn may regulate $\mathrm{IL}-1 \mathrm{R}$ expression [27]. There is no a priori reason to believe that the expression of a gene such as NLRP2 is affected by gender. If 
Figure 1

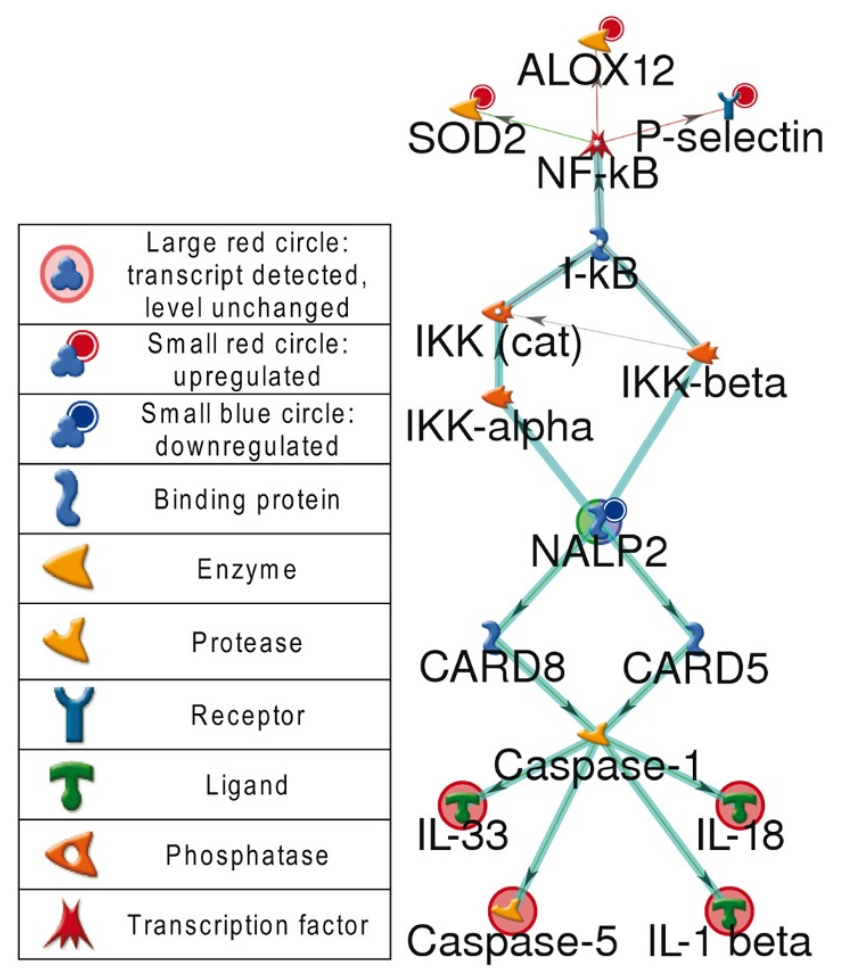

Network illustrating possible role of NALP2 (NLRP2) in SpA via routes leading to NFKB or caspase-1 activation. NLRP2 gene expression is reduced two-fold in axial spondyloarthropathy $(\mathrm{SpA})$ compared with controls. Image generated by GeneGo Metacore ${ }^{\mathrm{TM}}$ software [15].

NLRP2 is indeed under expressed in males, this downregulation may be an important clue to the male predominance in this disease.

Ossification is the hallmark of $\mathrm{SpA}$, but there is also ongoing bone resorption with up to $56 \%$ of patients becoming osteopenic and a significant proportion becoming osteoporotic [28]. The wnt-catenin pathway and its primary regulator Dickkopf 1 (DKK-1) regulate the balance between osteoblast and osteoclast function [29]. The upregulation of kremen1 in our data suggests negative regulation of the wnt-catenin pathway via its interaction with DKK-1. The net effect of this and other factors may be bone resorption [30]. Endogenous bone morphogenetic protein 6 (BMP6) has been described in a mouse model of enthesis ossification and shown to promote osteoblast differentiation. Inhibition of BMP6 prevents the onset and progress of an SpA-type model of arthritis [31].

This study has some limitations. Firstly, although the diagnosis of $\mathrm{SpA}$ was made using a validated method, it was not possible to grade disease activity because most patients were attending an eye clinic. Patients did not routinely have X-rays or MRI scans of the pelvis. However, nearly $100 \%$ of the patients had inflammatory lower back pain confirmed by a rheumatologist. Secondly, the control group consisted of volunteers with females outnumbering males. There was a predominance of males in the SpA group as is expected in this condition. Gender differences were apparent for a number of differentially expressed genes located on sex chromosomes. These gender-linked genes could be readily identified on the basis of their chromosomal location and they are not known to contribute to inflammation [see Additional data file 2]. A post hoc analysis was conducted on the transcripts selected as having higher or lower expression levels in SpA subjects to identify those that were also influenced by gender.

Statistical tests on the effect of gender and/or disease on gene expression revealed that disease, rather than the disproportionate number of males in the group with $\mathrm{SpA}$, accounted for the differences in gene expression. However, gender does play a role in $\mathrm{SpA}$, because the vast majority of patients with $\mathrm{SpA}$ are male. For some transcripts the overexpression or underexpression of a particular transcript in SpA is more apparent in males. The directional consistency of differences revealed by the initial SAM analysis and the secondary analysis add further support to our findings.

\section{Conclusions}

Despite the limitations mentioned above, this study has clearly identified a number of novel and intriguing potential contributors to SpA. Gene expression microarray may elucidate pathogenesis, facilitate diagnostic specificity, correlate with pharmacologic responsiveness, and predict prognosis. We based this study in an ophthalmology clinic to test the hypothesis that patients with SpA and active uveitis would express genes in peripheral blood to distinguish those with uveitis from those without uveitis. Our initial evaluation of this hypothesis indicates that a larger database is necessary to determine if such differences exist. This goal will require large databases with careful accrual of clinical data. We believe that the present study represents an important step toward understanding the molecular mechanisms of SpA.

\section{Competing interests}

$\mathrm{CH}$ has an equity interest (less than $\$ 5,000$ ) in Affymetrix Inc. None of the other authors has any competing interests.

\section{Authors' contributions}

CA recruited subjects and obtained informed consent, drew blood, conducted clinical data entry, and reviewed the manuscript. $\mathrm{CH}$ conducted experimental design, supervised microarray assays, conducted data interpretation, and contributed to the manuscript. DC conducted statistical analysis, and contributed to the manuscript. JL recruited subjects and obtained informed consent, drew blood, conducted clinical data entry, and reviewed the manuscript. JR conducted experimental design, examined patients, conducted data interpretation, edited the manuscript, and supervised the entire project. JS conducted experimental design, provided oversight for human 
subject research, conducted data interpretation, and edited the manuscript. SP conducted experimental design and database design, oversaw RNA extraction, conducted data interpretation, and contributed to manuscript editing. SS examined patients, analyzed data, and drafted the manuscript. TD extracted RNA from blood samples, and reviewed the manuscript. TM contributed to the manuscript.

\section{Additional files}

The following Additional files are available online:

\section{Additional file 1}

PDF file containing heatmaps illustrating expression of genes distinguishing control and axial

spondyloarthropathy (SpA) peripheral blood in Set 1 and Set 2.

See http://www.biomedcentral.com/content/ supplementary/ar2855-S1.pdf

\section{Additional file 2}

PDF file containing a table that lists probe sets indicating genes with significantly $(q<5 \%)$ higher or lower expression in patients with axial spondyloarthropathy compared with control subjects in Set 1 and Set 2. See http://www.biomedcentral.com/content/ supplementary/ar2855-S2.pdf

\section{Acknowledgements}

We are indebted to Atul Deodhar for identification of patients with SpA. Supported by NIH Grants EY015858 and EY010572; Research to Prevent Blindness Awards to the Casey Eye Institute and to JTR, SRP, and JRS; the Stan and Madelle Rosenfeld Family Trust; the Fund for Arthritis and Infectious Disease Research; the Schnitzer-Novack Foundation; and a Keeler Foundation Scholarship to SMS.

\section{References}

1. Baechler EC, Batliwalla FM, Karypis G, Gaffney PM, Ortmann WA, Espe KJ, Shark KB, Grande WJ, Hughes KM, Kapur V, Gregersen PK, Behrens TW: Interferon-inducible gene expression signature in peripheral blood cells of patients with severe lupus. Proc Natl Acad Sci USA 2003, 100:2610-2615.

2. Rudwaleit M, Khan MA, Sieper J: The challenge of diagnosis and classification in early ankylosing spondylitis: do we need new criteria? Arthritis Rheum 2005, 52:1000-1008.

3. Rudwaleit M, Metter A, Listing J, Sieper J, Braun J: Inflammatory back pain in ankylosing spondylitis: a reassessment of the clinical history for application as classification and diagnostic criteria. Arthritis Rheum 2006, 54:569-578.

4. Rudwaleit M, Baeten D: Ankylosing spondylitis and bowel disease. Best Pract Res Clin Rheumatol 2006, 20:451-471.

5. Bioconductor open source software for bioinformatics [http:/ /www.bioconductor.org]

6. Wu Z, Izarray RA, Gentleman R, Martinez-Murillo F, Spencer F: A model-based background adjustment for oligonucleotide expression arrays. J Am Stat Assoc 2004, 99:909-917.

7. Li C, Wong WH: Model-based analysis of oligonucleotide arrays: Expression index computation and outlier detection. Proc Natl Acad Sci USA 2001, 98:31-36.
8. Tusher VG, Tibshirani R, Chu G: Significance analysis of microarrays applied to the ionizing radiation response. Proc Natl Acad Sci USA 2001, 98:5116-5121.

9. Storey JD, Tibshirani R: Statistical significance for genomewide studies. Proc Natl Acad Sci USA 2003, 100:9440-9445.

10. Choi D, Sharma SM, Pasadhika S, Kang Z, Harrington CA, Smith JR, Planck SR, Rosenbaum JT: Application of biostatistics and bioinformatics tools to identify putative transcription factorgene regulatory network of ankylosing spondylitis and sarcoidosis. Commun Stat -- Theory and Methods 2009, 38:3326-3338.

11. Rosenbaum JT, Pasadhika S, Crouser ED, Choi D, Harrington CA Lewis JA, Austin CR, Diebel TN, Vance EE, Braziel RM, Smith JR, Planck SR: Hypothesis: Sarcoidosis is a STAT1-mediated disease. Clinical Immunology 2009, 132:174-183.

12. Nat. Center Biotech. Information Gene Expression Omnibus [http://www.ncbi.nlm.nih.gov/geo/]

13. Bolstad BM, Irizarry RA, Astrand M, Speed TP: A comparison of normalization methods for high density oligonucleotide array data based on variance and bias. Bioinformatics 2003, 19:185-193.

14. Akaike $\mathrm{H}$ : A new look at the statistical model identification. IEEE Trans Autom Control 1974, 19:716-723.

15. GeneGo bioinformatics software for systems biology \& drug discovery [http://www.genego.com/]

16. Nat. Center Biotech. Information PubMed [http:// www.ncbi.nlm.nih.gov/pubmed/]

17. Gu J, Marker-Hermann E, Baeten D, Tsai WC, Gladman D, Xiong M, Deister H, Kuipers JG, Huang F, Song YW, Maksymowych W, Kalsi J, Bannai M, Seta N, Rihl M, Crofford LJ, Veys E, De Keyser F, Yu DT: A 588-gene microarray analysis of the peripheral blood mononuclear cells of spondyloarthropathy patients. Rheumatology 2002, 41:759-766.

18. Sims AM, Timms AE, Bruges-Armas J, Burgos-Vargas R, Chou CT Doan T, Dowling A, Fialho RN, Gergely P, Gladman DD, Inman R, Kauppi M, Kaarela K, Laiho K, Maksymowych W, Pointon JJ, Rahman P, Reveille JD, Sorrentino R, Tuomilehto J, Vargas-Alarcon G, Wordsworth BP, Xu H, Brown MA: Prospective meta-analysis of interleukin 1 gene complex polymorphisms confirms associations with ankylosing spondylitis. Ann Rheum Dis 2008, 67:1305-1309.

19. Rahman P, Sun S, Peddle L, Snelgrove T, Melay W, Greenwood C, Gladman D: Association between the interleukin-1 family gene cluster and psoriatic arthritis. Arthritis Rheum 2006, 54:2321-2325.

20. Wellcome Trust Case Control Consortium, The Australo-AngloAmerican Spondylitis Consortium (TASC): Association scan of 14,500 nonsynonymous SNPs in four diseases identifies autoimmunity variants. Nat Genet 2007, 39:1329-1337.

21. Chen CH, Liao HT, Chen HA, Liang TH, Wang CT, Chou CT: Soluble triggering receptor expressed on myeloid cell-1 (sTREM1): a new mediator involved in early ankylosing spondylitis. $J$ Rheumatol 2008, 35:1846-1848.

22. Wang N, Thuraisingam T, Fallavollita L, Ding A, Radzioch D, Brodt $P:$ The secretory leukocyte protease inhibitor is a type 1 insulin-like growth factor receptor-regulated protein that protects against liver metastasis by attenuating the host proinflammatory response. Cancer Res 2006, 66:3062-3070.

23. Macko RF, Gelber AC, Young BA, Lowitt MH, White B, Wigley FM, Goldblum SE: Increased circulating concentrations of the counteradhesive proteins SPARC and thrombospondin- 1 in systemic sclerosis (scleroderma). Relationship to platelet and endothelial cell activation. J Rheumato/ 2002, 29:2565-2570.

24. Sangaletti S, Gioiosa L, Guiducci C, Rotta G, Rescigno M, Stoppacciaro A, Chiodoni C, Colombo MP: Accelerated dendritic-cell migration and T-cell priming in SPARC-deficient mice. $J$ Cell Sci 2005, 118:3685-3694.

25. Church LD, Cook GP, McDermott MF: Primer: inflammasomes and interleukin 1 beta in inflammatory disorders. Nat Clin Pract Rheumatol 2008, 4:34-42.

26. Bruey JM, Bruey-Sedano N, Newman R, Chandler S, Stehlik C Reed JC: PAN1/NALP2/PYPAF2, an inducible inflammatory mediator that regulates NF-kappaB and caspase-1 activation in macrophages. J Biol Chem 2004, 279:51897-51907.

27. Kinoshita T, Wang Y, Hasegawa M, Imamura R, Suda T: PYPAF3, a PYRIN-containing APAF-1-like protein, is a feedback regula- 
tor of caspase-1-dependent interleukin-1 beta secretion. $J$ Biol Chem 2005, 280:21720-21725.

28. Lange U, Kluge A, Strunk J, Teichmann J, Bachmann G: Ankylosing spondylitis and bone mineral density--what is the ideal tool for measurement? Rheumatol Int 2005, 26:115-120.

29. Goldring SR, Goldring MB: Eating bone or adding it: the Wnt pathway decides. Nat Med 2007, 13:133-134.

30. Mao B, Wu W, Davidson G, Marhold J, Li M, Mechler BM, Delius H, Hoppe D, Stannek P, Walter C, Glinka A, Niehrs C: Kremen proteins are Dickkopf receptors that regulate Wnt/beta-catenin signalling. Nature 2002, 417:664-667.

31. Lories RJ, Derese I, Luyten FP: Modulation of bone morphogenetic protein signaling inhibits the onset and progression of ankylosing enthesitis. J Clin Invest 2005, 115:1571-1579.

32. Nat. Center Biotech. Information Online Mendelian Inheritance in Man [http://www.ncbi.nlm.nih.gov/omim/] 